\title{
Performance of fiber reinforced open graded asphalt treated base
}

\section{TIAN Xiaoge ${ }^{1, *}, \quad$ CHU Yantian², ZHANG Ren ${ }^{3}, \quad$ YANG Zhen ${ }^{4}, \quad$ XV Yicao ZHENG Shaohua ${ }^{6}$}

\author{
School of Traffic \& Transportation, Changsha University of Science \& Technology, Changsha, \\ Hunan, P.R.China, 410114; Ph:013975115167;
}

1.tianxiaoge@126.com,2.1007879594@qq.com,3.1023232844@qq.com,4.251125117@qq.com, 5.1274637931@qq.com, 6.1150748228@qq.com

\begin{abstract}
Keywords: Asphalt treated base (ATB) ; Gradation optimization; drainage capacity; lignin fiber; reflection crack resistance; durability
\end{abstract}

Abstract: To enhance the durability of semi-rigid base asphalt pavement, it is suggested that the asphalt treated base (ATB) layer should have certain drainage capacity to eliminate the water inside the pavement, and the crack resistance of ATB mixture should be improved to prevent and/or delay the generation and propagation of reflection crack. So, a kind of fiber reinforced open graded ATB mixture, FATB-25, was optimized. Then, the seepage, anti-rutting and anti-reflective crack capacity were measured, which were compared with those of AC -25 and ATB-25. The results indicated that the drainage capacity of the optimized FATB-25 meets the requirements, and its rutting resistance, anti-fatigue properties and anti-reflective crack capacity were significant better than those of the contrast mixtures, AC-25 and ATB-25.

\section{INTRODUCTION}

In China, semi-rigid base courses were utilized in more than 90\% of asphalt pavement[1]. Semi-rigid base courses have greater strength and rigidity than asphalt treated base (ATB), unbound graded aggregate base or any other flexible base, it can more economically provide enough structural bearing capacity to heavy load traffic in our country. So it is suitable for China's economic and traffic conditions. However, semi-rigid materials are prone to shrinkage and/or temperature shrinkage cracking, resulting in the generation of reflective cracks in pavement, weaken the bearing capacity of the pavement structure, and inducing water seep into the inner of pavement[1]. At the same time, because that the moisture stability of semi-rigid materials is weak, water seeped into the internal structure, if not promptly removed, it will cause moisture damage, and will affect pavement performance and service life[2].

Aiming at moisture damage of asphalt pavement, Ridgeway pointed out that the most reliable drainage system is to adopt open graded drainage layer for the entire width under the pavement. Eliminating the water entered into the internal pavement structure rapidly is the basic requirement for pavement design [3]. Zhang Pengfei and Zhuang Shaoqin pointed out that the ATPB layer can effectively exclude the water inside the pavement structure according to observation results of the test road with porous ATB (ATPB) internal drainage system [4]. Zhang Pengfei studied the impact of various factors on ATPB porosity and permeability coefficient, strength etc. and pointed out that the large porosity $(>18 \%)$ affects the durability of ATPB[5].

Aiming at the problem of reflection crack in asphalt pavement, Dave[6] have studied deeply on the reflection cracking mechanism, anti-cracking measures, etc. and a variety of measures were put forward to avoid or delay generating or expanding of the reflective cracking [7]. The studies of Zhou et al showed that adding a layer of ATB between the semi-rigid layer and the bottom asphalt mixture layer is a more economical and effective anti-reflection crack measurement [8].

To solve the problem of moisture damage and reflection crack in semi-rigid base asphalt pavement, the gradation of ATB mixture was optimized with certain drainage ability and better crack resistance and durability, so as to reduce moisture damage and to prevent and/or delay reflection cracks. So, it can be utilized to ensure performance and to enhance durability of semi-rigid base asphalt pavement. 


\section{RAW MATERIALS}

\section{A. Asphalt}

Esso 70A was selected as the asphalt binder in accordance with Chinese Standard Test Methods of Bitumen and Bituminous Mixtures for Highway Engineering[9].

B. Aggregates and filler

All of the coarse aggregate, fine aggregate and filler used in the paper were made from limestone. in accordance with Chinese Test Methods of Aggregate for Highway Engineering[10]

C. Fiber

German JRS VIATOP premium wood fiber (table 1) was selected.

TABLE 1. TECHNICAL INDEXES OF JRS VIATOP PREMIUM LIGNIN FIBER

\begin{tabular}{|c|c|c|c|}
\hline Indexes & Units & Measured & Technical Requirements \\
\hline Fiber length & $\mathrm{mm}$ & $<6 \mathrm{~mm}$ & $\leq 6$ \\
\hline Ash content & $\%$ & 17.6 & $18 \pm 5$ \\
\hline PH value & - & 7.6 & $7.5 \pm 1.0$ \\
\hline Oil absorption rate & times of fiber mass & 5.8 & $\geq 5$ \\
\hline Moisture content (in mass) & $\%$ & 1.75 & $\leq 5$ \\
\hline
\end{tabular}

\section{GRADATION OPTIMIZATION OF FATB-25}

Two-segment gapped gradation design method was utilized to design the gradation of FATB[11].

1) The passing rates of three critical sieve sizes, $4.75 \mathrm{~mm}, 9.5 \mathrm{~mm}$ and the maximum nominal size, were preliminary determined. And then, the passing rate of $4.75 \mathrm{~mm}$ sieve size can be determined through completely or partially gapped according to the passing rate of $9.5 \mathrm{~mm}$.

2) The passing rates of coarse aggregates can be determined according to the passing rates of $9.5 \mathrm{~mm}$ and the maximum nominal size.

3) The passing rate of $0.075 \mathrm{~mm}$ sieve was selected as the maximum passing rate, $4 \%$, of the recommended range of $\mathrm{AM}-25$, and then the passing rates of fine aggregates were determined according to the passing rates of $4.75 \mathrm{~mm}$ and $0.075 \mathrm{~mm}$ sieves.

4) According to the calculated gradation, the coarse aggregates of each gradation were weighed and dry ramming tests were conducted, and the voids of coarse aggregates, VCA, were determined.

And then the theoretic porosity of the mixture was estimated according to the estimated content of asphalt binder. If the porosity is too small, reducing the passing rate of $4.75 \mathrm{~mm}$ to increase the contents of coarse aggregates and to reduce the contents of fine aggregates. If the porosity is too large, then increasing the passing rate of $4.75 \mathrm{~mm}$ to reduce the contents of coarse aggregate and to increase the contents of fine aggregates.

5) For those gradations whose calculation porosity is $8 \%$ to $12 \%$ ), the fiber content was draft determined, then Marshall tests were conducted to determine the optimum asphalt content.

6) Specimens were molded and various pavement performance were measured and were compared with those of AC-25 and ATB-25.

So, gradation of FATB-25 was designed (Table 2) and its volume indexes were measured by vacuum seal and weight-in-water method: Void of air, $\mathrm{v}_{\mathrm{a}}=9.7 \%$, Voids in the mineral aggregates, $\mathrm{VMA}=17.4 \%$, and Void filled with asphalt, VFA $=53.4 \%$. Its porosities meet the goal.

TABLE 2. GRADATION ADJUSTMENT PROCESS OF FATB-25

\begin{tabular}{|c|c|c|c|c|c|c|c|c|c|c|c|c|c|}
\hline Sieve sizes [mm] & $\mathbf{3 1 . 5}$ & $\mathbf{2 6 . 5}$ & $\mathbf{1 9}$ & $\mathbf{1 6}$ & $\mathbf{1 3 . 2}$ & $\mathbf{9 . 5}$ & $\mathbf{4 . 7 5}$ & $\mathbf{2 . 3 6}$ & $\mathbf{1 . 1 8}$ & $\mathbf{0 . 6}$ & $\mathbf{0 . 3}$ & $\mathbf{0 . 1 5}$ & $\mathbf{0 . 0 7 5}$ \\
\hline Passing Rate $(\%)$ & 100 & 95.3 & 78.2 & 59.7 & 40.3 & 22.5 & 19.0 & 15 & 12 & 8 & 5.5 & 4.8 & 4 \\
\hline
\end{tabular}

\section{PERFORMANCE TESTS}

The performance measured include water permeability, rutting, fatigue and anti-reflective crack ability, which were compared with those of the ordinary AC-25 and ATB-25. Gradations of AC-25 
and ATB-25 were shown in Table 3. Their optimal asphalt contents were $4.3 \%$ and $3.7 \%$, respectively, determined through the Marshall method.

TABLE 3. Gradation of COMPARATIVE Asphalt MiXTures AC-25 AND ATB-25

\begin{tabular}{|c|c|c|c|c|c|c|c|c|c|c|c|c|c|}
\hline Sieve sizes [mm] & $\mathbf{3 1 . 5}$ & $\mathbf{2 6 . 5}$ & $\mathbf{1 9}$ & $\mathbf{1 6}$ & $\mathbf{1 3 . 2}$ & $\mathbf{9 . 5}$ & $\mathbf{4 . 7 5}$ & $\mathbf{2 . 3 6}$ & $\mathbf{1 . 1 8}$ & $\mathbf{0 . 6}$ & $\mathbf{0 . 3}$ & $\mathbf{0 . 1 5}$ & $\mathbf{0 . 0 7 5}$ \\
\hline AC-25 & 100 & 95.6 & 84.3 & 72.9 & 59.9 & 48.3 & 34.3 & 22.4 & 15.6 & 10.2 & 6.9 & 5.1 & 4.0 \\
\hline ATB-25 & 100 & 93.5 & 80.5 & 65.8 & 52.0 & 40.1 & 29.3 & 20.5 & 15.6 & 11.8 & 8.3 & 6.3 & 3.8 \\
\hline
\end{tabular}

A. Permeability

Permeabilities were measured on plate samples [9]. The results were presented in table 4.

TABLE 4. PERMEABILITY OF DIFFERENT MIXTURES

\begin{tabular}{|c|c|c|c|}
\hline Mixtures & FATB-25 & AC-25 & ATB-25 \\
\hline permeability coefficient, $\mathrm{Cw} \quad[\mathrm{mL} / \mathrm{min}]$ & 455.3 & 39.5 & 116 \\
\hline
\end{tabular}

B. Anti-rut deformation performance

Rutting tests at $60^{\circ} \mathrm{C}$ were conducted to evaluate their high temperature deformation performance. The results were shown in Table 5.

TABLE 5. RUTTING RESULTS OF DIFFERENT MIXTURES

\begin{tabular}{|c|c|c|c|}
\hline Indexes & $\begin{array}{c}\text { Dynamic stability, DS } \\
\text { [cycles/mm] }\end{array}$ & $\begin{array}{c}\text { Max. rutting depth } \\
{[\mathbf{m m}]}\end{array}$ & $\begin{array}{c}\text { Relative deformation ratio } \\
{[\%]}\end{array}$ \\
\hline FATB-25 & 6270 & 1.38 & 1.73 \\
\hline ATB-25 & 4748 & 3.76 & 4.7 \\
\hline AC-25 & 3587 & 4.52 & 5.65 \\
\hline
\end{tabular}

It can be seen from Table 5 that the rut deformation of FATB-25 is obviously less than that of ATB-25 and AC-25, and the dynamic stability (DS) is obviously larger than that of ATB-25 and AC-25, which indicates that FATB-25 has better rutting resistant than that of ATB-25 and AC-25.

C. Anti-reflection crack capacity

According to the mechanism of reflection crack in asphalt pavement[1], test device shown in Figure 1 was developed to study the anti-reflective crack capacity of asphalt mixture. The specimen is $30 \mathrm{~cm}$ (length)* $6 \mathrm{~cm}$ (width), the thickness of asphalt mixture layer is $8 \mathrm{~cm}$, and the thickness of the cement concrete layer is $8 \mathrm{~cm}$. In the middle of the cement concrete layer, a fully penetrated crack (crack width of $1 \mathrm{~cm}$ ) was used to simulate the cracked semi-rigid base layer, and the rubber sheet was used to simulate the support of the soil base. An eccentric load or symmetrical load $(\mathrm{P}=0.7$ $\mathrm{MPa}$ ) was applied using MTS810.

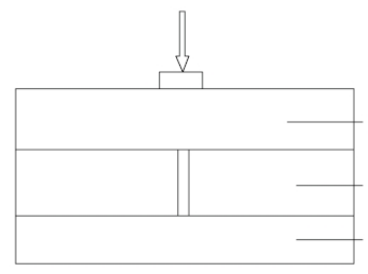

(a)

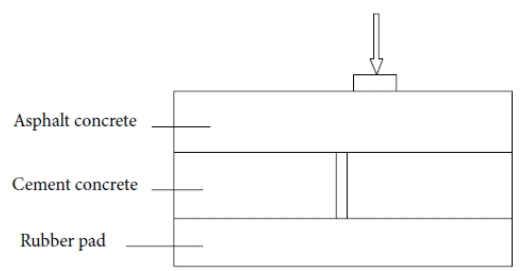

(b)

(a) Symmetric loading (flexural tensile)

(b) Eccentric loading (shear type)

FIGURE 1. LOADING TEST MODEL OF ANTI-CRACKING ABILITY OF ASPHALT MIXTURE

The loading times when the crack generate at the bottom of samples $\left(\mathrm{N}_{0}\right)$ and the sample completely broken $\left(\mathrm{N}_{\mathrm{f}}\right)$ were recorded. $\mathrm{N}_{0}, \mathrm{~N}_{\mathrm{f}}$ can be used as anti-reflective crack ability evaluation index of asphalt concrete. The results were shown in Table 6. 
TABLE 6. TEST RESULTS FOR ANTI-REFLECTIVE CRACK CAPACITY [Thousand Times]

\begin{tabular}{|c|c|c|c|c|}
\hline \multirow{2}{*}{ Gradation } & \multicolumn{2}{|c|}{ Symmetric loading (flexural tensile) } & \multicolumn{2}{c|}{ Eccentric loading (shear) } \\
\cline { 2 - 5 } & $\boldsymbol{N}_{\boldsymbol{0}}$ & $\boldsymbol{N}_{\boldsymbol{f}}$ & $\boldsymbol{N}_{\boldsymbol{o}}$ & $\boldsymbol{N}_{\boldsymbol{f}}$ \\
\hline AC-25 & 6.0 & 12.2 & 4.1 & 103.2 \\
\hline ATB-25 & 6.3 & 16.1 & 5.5 & 124.5 \\
\hline FATB-25 & 7.0 & 23.9 & 7.7 & 206.5 \\
\hline
\end{tabular}

It can be seen from Table 6 that: (1) the reflective crack resistance of FATB-25 is better than that of AC-25 and ATB-25; (2) the crack lives under shear-type loading are less than that under bend type loading, so the reflective crack resistance should be characterized under shear-type loading.

\section{Four-point bending fatigue test}

The dimensions of samples are $300 \mathrm{~mm} * 60 \mathrm{~mm} * 80 \mathrm{~mm}$. and the test conditions are unified: $20^{\circ} \mathrm{C}$, loading frequency is $10 \mathrm{~Hz}$, sine wave, $\mathrm{P}_{\min } / \mathrm{P}_{\max }=0.3 \mathrm{kN} / 3 \mathrm{kN}=0.1$. Test results are shown in Table 7 .

TABLE 7. FOUR-POINT BENDING FATIGUE LIVES

\begin{tabular}{|c|c|c|c|}
\hline Gradation & AC-25 & ATB-25 & FATB-25 \\
\hline Fatigue lives(cycles) & 437 & 372 & 1264 \\
\hline
\end{tabular}

As can be seen from table 7 that fatigue resistance of FATB-25 is significantly better than that of AC-25 and ATB-25, about three times than that of AC-25 and Four times than that of ATB-25.

\section{CONCLUSIONS}

1) It is suggested that the ATB layer should have a certain drainage capacity and great crack resistance to avoid or delay the generation or expansion of reflective cracks in asphalt pavement.

2) The gradation design method and design process of FATB were put forward based on the volume design method.

3) The designed FATB-25 has better rutting, reflection crack and fatigue resistance.

\section{REFERENCES}

[1] XU Hua. Reflective crack propagation and fatigue life for asphalt concrete pavement on semi-rigid base course[D]. Nanning: Guangxi University, 2012.

[2] JI Qingke. Design of pavement subsurface drainage system[D]. Shanghai:Tongji Univ., 2002

[3] Ridgeway, H.H. Synthesis of highway practice 96: pavement subsurface drainage systems. TRB, National Research Council, Washington, D.C. Nov., 1982

[4] ZHANG Pengfei,ZHUANG Shaoqin. Construction of test pavement with internal drainage system of multi-void asphalt stabilized macadam base[J]. Highway. 1998,(6):28-32.

[5] ZHANG Pengfei. Design and study of pavement subsurface drainage system[D]. Shanghai:Tongji Univ.,1999

[6] Dave E. V, Buttlar W. G. Thermal reflective cracking of asphalt concrete overlays [J]. International Journal of Pavement Engineering. 2010,11(6): 477-488.

[7] Lee H. J., Lee J. H., Park H.M. Performance evaluation of high modulus asphalt pavements for long life asphalt pavement. Construction and Building Materials. 2007,21(5):1079-1087.

[8] Zhou Chuanming, Han Chao and Yongsheng. Structural Analysis and Development Trend Research on Combined Base Asphalt Pavement. Petroleum Asphalt, 2014, 28(4): 29-32.

[9] JTG E20-2011. Standard Test Methods of Bitumen and Bituminous Mixtures for Highway Engineering[S]. 2011 
[10] JTG E42-2005. Test methods of aggregate for highway engineering[S]. 2005

[11] LU Huazhen, CHEN Fei. Study on volume design method of variable k-method intermittent aggregate[J]. Journal of Highway and Transportation. 2010.72(12):190-192 